\title{
Self-Organizing Map-based Applications in Remote Sensing
}

\author{
Anthony Filippi ${ }^{1}$, Iliyana Dobreva ${ }^{1}$, \\ Andrew G. Klein ${ }^{1}$ and John R. Jensen ${ }^{2}$ \\ ${ }^{1}$ Department of Geography, Texas AEM University \\ ${ }^{2}$ Department of Geography, University of South Carolina
}

USA

\section{Introduction}

Remote sensing involves the collection of information about an object from a distance. Often remote-sensing instruments are mounted onboard an air- or space-borne platform and typically record electromagnetic energy in specific wavelength intervals, or bands. The electromagnetic energy recorded over a given area contains information about surfaces reflecting or emitting energy. This information can be used for a variety of applications; for example, remote-sensing image analysis can extract thematic information such as land-cover types (Jensen, 2005).

Artificial neural network (ANN) techniques have increasingly been employed in the analysis of remotely-sensed images. ANNs can be advantageous in digital image processing in that no assumption is made about the statistical properties of the images, and they are thus widely applicable to a variety of dataset types. In addition, ANNs learn adaptively through examples and have a high tolerance to noisy or incomplete data (Jensen, 2005). ANN model development can proceed via either supervised or unsupervised means, and if adequate training data are available, supervised training may be readily performed. However, obtaining reliable training data in remote-sensing applications is often problematic (Congalton and Green, 1999), as a remote sensor image typically covers a large area, and only a limited number of training locations can be sampled in the field due to cost, time, personnel requirements, and various other logistical constraints, including potential restrictions on access to the study area. Unsupervised image-processing methodsincluding unsupervised ANNs - can be of significant utility in such circumstances (Filippi et al., 2009). Unsupervised ANNs are used in situations where the correct outputs may not be known, or if it is desired that the network discover or categorize regularities or features in the training data on its own. There is no teacher signal (Hassoun, 1995).

The unsupervised Kohonen self-organizing map (SOM) is a two-layer network, with an input fan-out layer, and an output layer (known as the Kohonen or competitive layer), and the method is based upon competitive learning. The Kohonen layer is comprised of a physical net of neurons located at fixed positions (i.e., intersections in a grid of square meshes). Adjacent neurons are assumed to have a Euclidean distance of unity. The input 
layer has the same dimensionality as the pattern (feature) vector. The primary goal of the SOM is to capture the topology and model the probability distribution of the input vectors around the unit circle or hypersphere. The weight vectors act as a model for the probability distribution function. In an adaptive and topologically-ordered manner, the SOM converts patterns of arbitrary dimensionality (the pattern space) into the responses of one- or twodimensional virtual arrays of self-organizing neurons (feature space), which are essentially probability distribution maps. This feature-mapping component reduces the dimensionality. It is a topology-preserving map, as it preserves the neighborhood relations of the input pattern. Input and output neurons are fully connected via the synaptic weights (Kohonen, 1988; Lin and Lee, 1996; Haykin, 2009).

Self-organization involves adaptively modifying the synaptic weights as a result of input excitations while abiding by a learning rule until a useful configuration is produced. In the output layer, or lattice, output neurons become selectively tuned to the presented input patterns during a competitive-learning procedure. The topologically-ordered output space entails neurons close to one another representing similar input patterns. Learning is accomplished by first choosing an output neuron that most closely matches the presented input pattern, then determining a neighborhood of excited neurons around the winner, and finally, updating all of the excited neurons (Haykin, 2009). Learning decreases with intercellular distance; the nearest neighbors to the primary classifying cell learn the pattern very well, while more distant cells learn the pattern less well (Hassoun, 1995).

Supervised learning may also be incorporated through a related technique referred to as Learning Vector Quantization (LVQ). Similar to SOM, all output nodes compete and the winning node is selected according to its similarity with the presented input pattern. Unlike SOM though, only the winning neuron is updated, and thus, the resulting output feature space is not topologically ordered (Kohonen, 2001). If training data are available, often the SOM analysis is performed first, and then LVQ is applied to fine-tune the feature map.

This chapter provides a brief overview of the applications of SOM-based techniques and related self-organizing methods used in remote sensing, and it demonstrates the use of SOMs in remote sensing through a case study involving the classification of a Landsat Enhanced Thematic Mapper Plus (ETM+) surface reflectance image.

\section{Overview of SOM-based and SOM-related Applications in Remote Sensing}

The basic unsupervised SOM algorithm has been applied in various remote-sensing studies (Table 1). For example, it has been used for identifying characteristics ocean current patterns over semidiurnal, diurnal and sub-tidal time scales (Liu et al., 2006) and for identifying synoptic-scale wind patterns and sea surface temperature patterns (Richardson et al., 2003). In another oceanographic remote-sensing study, Marques and Chen (2003) proposed a Kohonen SOM-based approach for detecting the borders of eddies in the Mediterranean. These Mediterranean Water Eddies strongly affect Atlantic Ocean hydrodynamics and are important in the transport of particles, live organisms, and suspended material. The objective was to discover image pixels on cluster boundaries, rather than the clusters themselves. Compared with a conventional Canny gradient edge-detector, the SOM detected the more significant and continuous borders. The Canny algorithm did not detect all borders at high threshold values and generated excessive noise at low threshold values. The SOM was thus more robust to noise and ill-defined/amorphous borders (Marques and 
Chen, 2003). SOMs have also been used in synoptic climatology to locate archetypal points describing the multi-dimensional distribution function of gridded sea level pressure data. In Hewitson and Crane (2002), the SOM nodes represented important regional-scale circulatory features. Boekaerts et al. (1995) used an unsupervised, one-dimensional SOM in an autoadaptive mono-spectral cloud identification scheme employing Meteosat imagery. In terrestrial remote sensing, atmospheric features often constitute a source of noise, and minimizing such effects are typically desirable. For instance, monitoring vegetation cover and bare agricultural soils during the intercrop season is important for soil and water quality-management purposes, particularly in agriculture-intensive areas. Latif et al. (2008) identified and monitored bare soil interannual spatial variation at the regional scale using low-resolution satellite time-series data; however, such images are often adversely affected by clouds and shadows. The SOM was used to predict spectral values of pixels contaminated by weather conditions (i.e., clouds and cloud shadows) for posterior bare-soil mapping (Latif et al., 2008). In other terrestrial applications, the SOM algorithm has also been applied to detecting and characterizing yardangs, which are streamlined, elongated, wind-abraded ridges (Ehsani and Quiel, 2008), as well as to land-cover classification in an agricultural region and mapping fire-damaged forests (Furrer et al., 1994). Additionally, Kohonen's SOM has been used for automatically generating texture-based visual thesauri of massive archives remote-sensor images (e.g., aerial photographs and Advanced Very-High Resolution Radiometer (AVHRR) images) (Ramsey et al., 1999).

\begin{tabular}{|l|r|l|}
\hline \multicolumn{1}{|c|}{ Authors } & Year & \multicolumn{1}{c|}{ Application } \\
\hline $\begin{array}{l}\text { Ehsani and } \\
\text { Quiel }\end{array}$ & 2008 & Detecting and characterizing yardangs \\
\hline Latif et al. & 2008 & $\begin{array}{l}\text { Predicting spectral values of data contaminated by } \\
\text { weather conditions }\end{array}$ \\
\hline Liu et al. & 2006 & $\begin{array}{l}\text { Identifying ocean current patterns over semidiurnal, } \\
\text { diurnal and sub-tidal time scales }\end{array}$ \\
\hline $\begin{array}{l}\text { Marques and } \\
\text { Chen }\end{array}$ & 2003 & Detecting Mediterranean Water Eddy borders \\
\hline $\begin{array}{l}\text { Richardson et } \\
\text { al. }\end{array}$ & 2003 & $\begin{array}{l}\text { Identifying synoptic-scale wind patterns and sea surface } \\
\text { temperature patterns }\end{array}$ \\
\hline $\begin{array}{l}\text { Hewitson and } \\
\text { Crane }\end{array}$ & 2002 & Synoptic climatology \\
\hline Ramsey et al. & 1999 & $\begin{array}{l}\text { Creating texture-based visual thesauri of image } \\
\text { collections }\end{array}$ \\
\hline Boekaerts et al. & 1995 & Cloud identification \\
\hline Furrer et al. & 1994 & $\begin{array}{l}\text { Mapping fire-damaged forests; agricultural/land-cover } \\
\text { classification }\end{array}$ \\
\hline
\end{tabular}

Table 1. Basic SOM used in various example remote-sensing application domains

Applications of SOM variants in remote sensing have also been demonstrated (Table 2), and such SOM variants have been prompted by SOM limitations. For example, although the SOM has been a stable ANN model in high-dimensional data analysis, its utility is limited 
by its static network architecture and its limited ability to represent hierarchical relations in the data (Hong et al., 2006). Thus, a growing hierarchical SOM (GHSOM) has been proposed that employs a hierarchical structure comprised of multiple layers, where each layer is composed of one or more SOMs. Based on the input data distributions, the size of the sublayers dynamically adapts during network learning, and feature maps are added as needed. This layered architecture explicitly represents hierarchical relations between input data (Hong et al., 2006). The GHSOM is advantageous for processing large remote-sensor data sets and increasing image classification accuracy (Liu et al., 2006). GHSOM has been applied to the problem of cloud classification in satellite images (Hong et al., 2006) and the analysis of sea surface temperature patterns (Liu et al., 2006). Growing SOM (GSOM) changes its structure during the learning process by adding neurons to the output space, and it was successfully applied to the problem of unsupervised classification of a multispectral Landsat Thematic Mapper (TM) image (acquired over Colorado, USA, with multiple vegetation and soil classes) and a hyperspectral Airborne Visible/Infrared Imaging Spectrometer (AVIRIS) scene (acquired over the Lunar Crater Volcanic Field (LCVF), Nevada, USA, which is dominated by mineralogic/geologic materials) (Vilmann et al., 2003). Another SOM variant involves magnification control through the use of an additional magnification control parameter, and the technique was applied to the same Landsat TM and AVIRIS scenes as GSOM (Vilmann et al., 2003). Another SOM variant, Multiple SOMs (MSOMs), fuse several small feature maps, each explicitly representing different cluster regions, thus better approximating each region, and thus better dealing with region borders (Wan and Fraser, 1999; Wan and Fraser, 2000). MSOMs vary in the type of SOM used and in the way the small feature maps are fused, which can be performed in accordance with unsupervised, supervised, or hybrid methods. MSOMs have been used for multisource data fusion and compound classification of a bitemporal, agricultural remote-sensor image data set (Wan and Fraser, 1999). In Wan and Fraser (2000), the applicability of MSOMs was demonstrated through land-cover classification of an AVIRIS image and a joint spatio-temporal classification of two Landsat TM images. A modified SOM based on the work of Hillermeier et al. (1994), which introduced self-organized lateral network connections, has also been used to perform land-cover classification, including mapping fire-damaged forests (Olbert et al., 1995; Schaale and Furrer, 1995).

Whereas the above studies demonstrate the applicability of SOM variants to remote-sensing image analysis, other studies specifically modify the basic/original SOM for achieving specialized tasks. For example, the Self-Organized Road Mapping (SORM) algorithm was developed for road extraction from high-resolution multispectral images where a preclassified image is used as the input to a K-medians clustering algorithm, and the cluster locations are used as the input to a modified one-dimensional SOM (Doucette et al., 2008). Another SOM variant, the PicSOM, is used for the identification of specified anthropogenic structures such as buildings and for change detection using high-resolution images (Molinier et al., 2007). The technique involves the decomposition of images into subsets representing different structures and storing them in an image database. The stored image subsets are then used for SOM training, which subsequently allows for querying the image database for spatial structures of interest.

Supervised SOM is achieved by first coarse-tuning the feature map through unsupervised learning, and then fine-tuning the map using any supervised LVQ learning method (Kohonen, 1988). During LVQ training, the weights of the reference nodes are updated 


\begin{tabular}{|c|c|c|c|}
\hline Authors & Year & SOM Variant & Application \\
\hline Doucette et al. & 2008 & SORM & Road extraction \\
\hline Molinier et al. & 2007 & PicSOM & $\begin{array}{l}\text { Detection of buildings; } \\
\text { change detection }\end{array}$ \\
\hline Hong et al. & 2006 & GHSOM & Cloud characterization \\
\hline Liu et al. & 2006 & GHSOM & $\begin{array}{l}\text { Sea surface temperature } \\
\text { pattern analysis }\end{array}$ \\
\hline Vilmann et al. & 2003 & $\begin{array}{l}\text { GSOM } \\
\text { Magnification control }\end{array}$ & Land-cover classification \\
\hline Wan and Fraser & 2000 & MSOMs & $\begin{array}{l}\text { Joint spatio-temporal } \\
\text { agricultural classification }\end{array}$ \\
\hline Wan and Fraser & 1999 & MSOMs & $\begin{array}{l}\text { Multisource data fusion and } \\
\text { joint spatio-temporal } \\
\text { agricultural classification }\end{array}$ \\
\hline Olbert et al. & 1995 & $\begin{array}{l}\text { Population-coded, one- } \\
\text { layer model of } \\
\text { associative memory }\end{array}$ & $\begin{array}{l}\text { Mapping fire-damaged } \\
\text { forests }\end{array}$ \\
\hline $\begin{array}{l}\text { Schaale and } \\
\text { Furrer }\end{array}$ & 1995 & $\begin{array}{l}\text { Population-coded, one- } \\
\text { layer model of } \\
\text { associative memory }\end{array}$ & $\begin{array}{l}\text { Mapping fire-damaged } \\
\text { forests; land cover } \\
\text { classification }\end{array}$ \\
\hline
\end{tabular}

Table 2. Example SOM variants applied to remote sensing

according to samples of specified classes. The originally-proposed LVQ1, LVQ2, and LVQ3 learning methods and their modifications have been applied to remote-sensing problems (Table 3). Fine-turning the classification of a Landsat TM image with LVQ performed better than a maximum likelihood classification (MLC) (Ji, 2000). Generalized relevance LVQ (GRLVQ) combines two important modifications of the Kohonen LVQs (Villmann et al., 2003). First, the cost function is minimized through stochastic gradient descent, and second, input weights are applied to obtain scaling of the input dimensions. In Villmann et al. (2003), GRLVQ was applied to Landsat TM and AVIRIS images for the purposes of landcover/vegetation classification and geologic-mapping, respectively. The results were compared to the results obtained through GSOM and Magnification Control SOM (noted above), and it was demonstrated that GRLVQ produced the highest classification accuracy (Villmann et al., 2003). GRLVQ was further improved for use with high-dimensional hyperspectral images (Mendenhall and Merényi, 2008). GRLVQ Improved (GRLVQI) addresses the problem of poorly-utilized neurons by modifying the selection of winning neurons to encourage selection of infrequent winners. The technique was applied to a hyperspectral geologic AVIRIS image of the Lunar Crater Volcanic Field (LCVF) (noted above), and it was determined that higher classification accuracy can be obtained with GRLVQI relative to GRLVQ. The authors showed that relevance-selected features maintain or improve the performance of even basic classifiers (Mendenhall and Merényi, 2008). 


\begin{tabular}{|l|l|l|l|}
\hline \multicolumn{1}{|c|}{ Authors } & Year & \multicolumn{1}{c|}{ Technique } & \multicolumn{1}{c|}{ Application } \\
\hline $\begin{array}{l}\text { Mendenhall } \\
\text { and Merenyi }\end{array}$ & 2008 & GRLVQI & Land-cover classification \\
\hline Vilmann et al. & 2003 & GRLVQ & Land-cover classification \\
\hline Ji & 2000 & SOM/LVQ & Land-cover classification \\
\hline
\end{tabular}

Table 3. Supervised LVQ applications in remote sensing

The Kohonen self-organizing feature map, also referred to as the Kohonen clustering network (KCN) (Lin and Lee, 1996), exhibits some advantageous properties. For instance, weight vectors work to represent the natural tendency of a cluster of data points. It is unsupervised in that it requires no "teacher" during learning. $\mathrm{KCN}$ inherently reduces the dimensionality of the data by compressing and mapping it to the Kohonen layer, or mapping cortex. In addition, it always orients itself along the principal axes, but does not require the orthogonal and linear assumptions of standard principal component analysis (PCA). Thus, superior performance can be accrued when arbitrarily deformed distributions are present (Schaale and Furrer, 1995). And finally, KCN utilizes a parallel architecture, and it provides a graphical organization of topologically-preserved relationships. However, the $\mathrm{KCN}$ also entails several significant disadvantages: $\mathrm{KCN}$ is sequential, the termination strategy is artificial, and parameters such as the learning rate and the neighborhood size are selected heuristically, which does not ensure optimal performance. Convergence can be slow, and the network may not necessarily handle complexity accurately (Tsao et al., 1994).

Therefore, some attempts have been made in the ANN literature to address these disadvantages. For instance, Huntsberger and Ajjimarangsee (1990) first proposed a scheme that was essentially a partial integration of $\mathrm{KCN}$ and fuzzy c-means clustering (FCM), where the learning rates $\left\{a_{i k}\right\}$ were replaced with fuzzy membership values $\left\{u_{i k, t}\right\}$ calculated with FCM. This approach was referred to as the Partial Fuzzy Kohonen Clustering Network (PFKCN). One extra layer, a membership layer, was added to the output layer, or distance layer, of the original $\mathrm{KCN}$. The output $u_{i k}$ represented the degree to which the input pattern $x_{k}$ belonged to cluster $I$. During the learning process, however, in order to derive cluster centers that are the same as those of the FCM algorithm, it was necessary to feed these outputs back to update the cluster centers via a feedback path (Huntsberger and Ajjimarangsee, 1990). Note that $m$, the weighting exponent, still had to be chosen, and the approach lacked theoretical foundations and formal derivations (Bezdek and Pal, 1995). No properties pertaining to convergence were established; termination was forced. The fuzzy LVQ (FLVQ) algorithm (Bezdek and Pal, 1995) addresses these PFKCN shortcomings. Baraldi et al. (1998) gives a comparison of the properties of SOM and FLVQ algorithms.

Approaches based on the integration of ANN learning and fuzzy systems have been investigated in remote-sensing application domains (Table 4). Unsupervised fuzzy LVQ (FLVQ) combines FCM and unsupervised LVQ, and the technique has been applied to the task of coastal vegetation classification using hyperspectral AVIRIS surface reflectance image data (Filippi and Jensen, 2006). The effect of using continuum-removed AVIRIS image spectra as input to FLVQ for the same task was investigated in Filippi and Jensen (2007). Membership values are calculated for pixels according to a fuzzy c-partitioning of the 
feature space, where, in a remote-sensing context, the feature vectors correspond to the set of input image bands (Filippi and Jensen, 2006). A modification of FLVQ incorporates Gaussian membership functions for calculating fuzzy membership grades for input pixels and consequently uses fuzzy membership grade and not Euclidean distance to estimate closeness of input pixels to output clusters (Qui and Jensen, 2004). Since Gaussian membership functions are used in fuzzifying Kohonen's LVQ2 algorithm, the Gaussian LVQ (GLVQ) employs supervised learning, though it can internally utilize unsupervised learning to generate natural clusters. Further modification of GLVQ uses training data to initialize the weights of the network and also ensures that only the winning neuron is updated (Qui, 2008). The improved GLVQ has been applied to Hyperion satellite image land-cover classification and achieved better classification accuracy compared to standard hyperspectral classification algorithms. Other FLVQ studies include Blonda et al. (1995) and Ceccarelli et al. (1995), where it was employed for Landsat image segmentation and SAR texture data classification; FLVQ was then known as the fuzzy Kohonen clustering network (FKCN). Baraldi et al. (1998) used FLVQ and SOM to classify 18 multitemporal Landsat TM bands into general land-cover categories. Benz (1999) proposed an adaptive system that integrated FLVQ with a supervised fuzzy distribution estimator to classify single- and multi-channel SAR data to identify flooded areas, water, and various land-cover classes.

FLVQ employs fuzziness in the learning rate and update strategies, but not typically in producing fuzzy outputs (Filippi and Jensen, 2006). Thus, remote-sensing studies utilizing FLVQ and related algorithms usually generate crisp, or hard, image classification results.

\begin{tabular}{|l|c|l|l|}
\hline \multicolumn{1}{|c|}{ Authors } & Year & \multicolumn{1}{|c|}{ Technique } & \multicolumn{1}{c|}{ Application } \\
\hline Qui & 2008 & GFLVQ Modified & Land-cover classification \\
\hline Filippi and Jensen & 2007 & FLVQ & $\begin{array}{l}\text { Coastal vegetation classification } \\
\text { with continuum-removed } \\
\text { spectra }\end{array}$ \\
\hline Lee and Lathrop & 2006 & SOM-LVQ-GMM & Subpixel land cover \\
\hline Filippi and Jensen & 2006 & FLVQ & Coastal vegetation classification \\
\hline Qui and Jensen & 2004 & GFLVQ & Land-cover classification \\
\hline Benz & 1999 & $\begin{array}{l}\text { FLVQ integrated } \\
\text { fith supervised } \\
\text { estimator }\end{array}$ & $\begin{array}{l}\text { Flooded-area and land-cover } \\
\text { classification }\end{array}$ \\
\hline Baraldi et al. & 1998 & FLVQ and SOM & Land-cover classification \\
\hline Ceccarelli et al. & 1995 & FKCN/FLVQ & Land-cover classification \\
\hline Blonda et al. & 1995 & FKCN/FLVQ & Land-cover classification \\
\hline
\end{tabular}

Table 4. Fuzzy LVQ and related studies in remote sensing 
Subpixel image analysis estimates the percentage of different land covers within a pixel. To estimate the percent cover of impervious surface, lawn, and woody tree cover in urban/suburban areas, Lee and Lathrop (2006) fine-tune a SOM with LVQ and then construct a Gaussian kernel density function for each SOM node. Using the Gaussian Mixture Model, the posterior probabilities of the land-cover classes were computed for each pixel. To apply the proposed approach to subpixel analysis, the authors equated the percent land-cover type composition with the posterior probability.

Other hybrid techniques have been used in remote sensing (Table 5). SOM, LVQ, fuzzy clustering, and parametric and non-parametric Bayesian approaches are used for deriving clusters, and selection of the best partitioning is accomplished through fuzzy multi-criteria decision-making (Guijarro and Pajares, 2009). The technique is applied to texture extraction from natural images. In Gonçalves et al. (2008), cluster analysis was performed on a set of SOM prototypes, rather than operating directly upon the original image patterns. Specifically, SOM was applied first; agglomerative hierarchical clustering with restricted connectivity was then applied to the SOM grid. Another hybrid approach uses wavelet fusion as a pre-processing step, and the results are used as input to SOM, which is then finetuned through LVQ (Bagan et al., 2008). Applying the technique for land classification of an ASTER image improved classification accuracy compared to using the original ASTER reflectance bands as input. A cascaded architecture of neural fuzzy neural networks with feature mapping (CNFM) involves feature extraction from multispectral images and inputting the features to an unsupervised SOM, which performs dimensionality reduction; the result is fed to a supervised neural fuzzy network which performs final clustering (Lin et al., 2000). Other attempts have also involved the Kohonen SOM being used for initial clustering as part of a modular network architecture, e.g., where supervised approaches have utilized a self-organizing component. Yoshida and Omatu (1994) used the SOM for initial clustering before the data was fed into a Multiple-Layer Feedforward Network (MLFN) trained with back-propagation (BP); in concert with geographical data, training areas were selected more precisely using the clustering results from the SOM. Blonda et al. (1996) used the Kohonen SOM as part of a modular neural classification system. A singlelayer perceptron (SLP) (i.e., a multilayer perceptron (MLP) with no hidden neurons) was used as the supervised module. In another study, the weights at convergence of a Kohonen's self-organizing module have been used to initialize the weights between the input and hidden layers of a backpropagation ANN; this markedly increased the convergence rate, and thus decreased backpropagation network training time (Li and $\mathrm{Si}, 1992)$. Solaiman and Mouchot (1994) compared the MLC with the Kohonen SOM, LVQ2, MLP, and an unsupervised/supervised hybrid HLVQ network (consisting of an unsupervised SOM and a supervised LVQ2 network) in classifying an agricultural Landsat TM scene. In general, the hybrid method and the MLC produced the best results, but the SOM was comparable. These methods exceeded the classification accuracy of the MLP by about $10 \%$. Ito and Omatu (1997) partitioned the training data to where a separate self-organizing competitive layer was assigned to each class. Once training was completed, a $k$-nearest neighbor approach was invoked such that $k$ winner neurons were selected in order of minimum distance between the input vectors and the neuron weights. Although an artificial convergence criterion was used during self-organization, favorable results were still obtained. These modular systems have generally been successful when applied to multispectral remote-sensor images. 


\begin{tabular}{|c|c|c|c|}
\hline Authors & Year & Technique & Application \\
\hline $\begin{array}{l}\text { Guijarro and } \\
\text { Pajares }\end{array}$ & 2009 & \begin{tabular}{|l} 
Fuzzy Multicriteria \\
Decision Making Approach
\end{tabular} & $\begin{array}{l}\text { Classifying textures in natural } \\
\text { images }\end{array}$ \\
\hline $\begin{array}{l}\text { Gonçalves et } \\
\text { al. }\end{array}$ & 2008 & $\begin{array}{l}\text { SOM and agglomerative } \\
\text { hierarchical clustering }\end{array}$ & Land-cover classification \\
\hline Bagan et al. & 2008 & $\begin{array}{l}\text { Wavelet Fusion and } \\
\text { SOM/LVQ }\end{array}$ & Land-cover classification \\
\hline Lin et al. & 2000 & CNFM & Land-cover classification \\
\hline $\begin{array}{l}\text { Ito and } \\
\text { Omatu }\end{array}$ & 1997 & $\begin{array}{l}\text { Self-organizing neural } \\
\text { network and } k \text {-NN }\end{array}$ & $\begin{array}{l}\text { Urban land-cover } \\
\text { classification }\end{array}$ \\
\hline Blonda et al. & 1996 & SOM and SLP & Land-cover classification \\
\hline $\begin{array}{l}\text { Solaiman } \\
\text { and Mouchot }\end{array}$ & 1994 & $\begin{array}{l}\text { Hybrid HLVQ (SOM and } \\
\text { supervised LVQ2 network) }\end{array}$ & Agricultural classification \\
\hline $\begin{array}{l}\text { Yoshida and } \\
\text { Omatu }\end{array}$ & 1994 & SOM and MLP & Land-cover classification \\
\hline $\mathrm{Li}$ and $\mathrm{Si}$ & 1992 & \begin{tabular}{|l|} 
Self-Organizing \\
Backpropagation (SOBP)
\end{tabular} & Land-cover classification \\
\hline
\end{tabular}

Table 5. SOM hybrid studies in remote sensing

\section{Unsupervised Classification of Landsat ETM+ Image Data Using SOM}

An unsupervised snow-cover classification of a Landsat 7 ETM+ image demonstrates the application of SOM in remote sensing.

\subsection{Data description}

The Landsat ETM+ image used in the study was acquired on 27 March, 2002 and covers part of Wisconsin and Minnesota. The National Land Cover Database (NLCD) 2001 shows the predominant land covers as agricultural (cultivated crops, pasture/hay) and deciduous forest (Figure 1) (MRLC, 2009). The Mississippi River and several of its tributaries are notable spatial features in the scene. Snow cover is present in the northern half of the image and is easily distinguishable in cyan in a false-color composite of Landsat 7 ETM+ bands 5, 4 and 2 as R,G,B (Figure 2).

Landsat 7 ETM+ was launched in 1999 by National Aeronautics and Space Administration (NASA) and images the Earth once every 16 days in eight spectral bands (NASA, 2009). Bands 1-5 and band 7 have spatial resolution at nadir of 30 meters; band 6, which is a thermal infrared band, has a 60-meter resolution; and band 8, a panchromatic band, has 15meter resolution. Bands 1-3 record electromagnetic energy in the visible portion of the spectrum, band 4 in the near-infrared, and bands 5 and 7 in the short-wave infrared. Bands 6 and 8 were not used in the study because of the difference in spatial resolution. The six bands used in the study (Table 7) were first scaled to radiance, then an atmospheric correction was applied using the MODTRAN4 radiation transfer code (Jensen, 2005), and the image was georegistered to an orthorectified Landsat ETM+ image. 


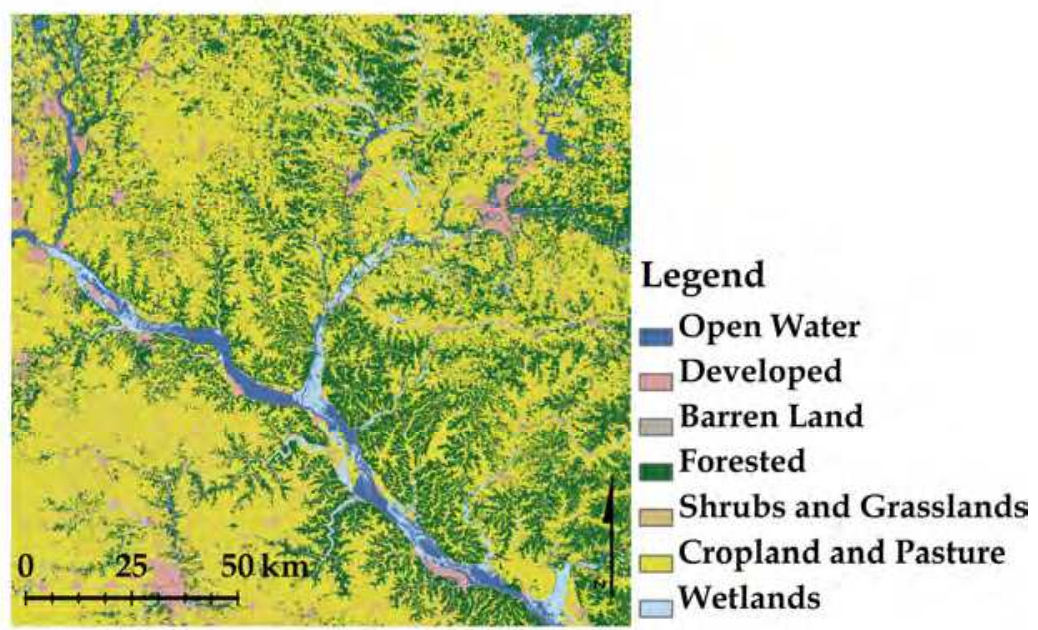

Fig. 1. Predominant land covers in the scene are cultivated crops, pasture/hay, and deciduous forests. The Mississippi River and some of its tributaries are major spatial features (Source: NLCD, 2001).

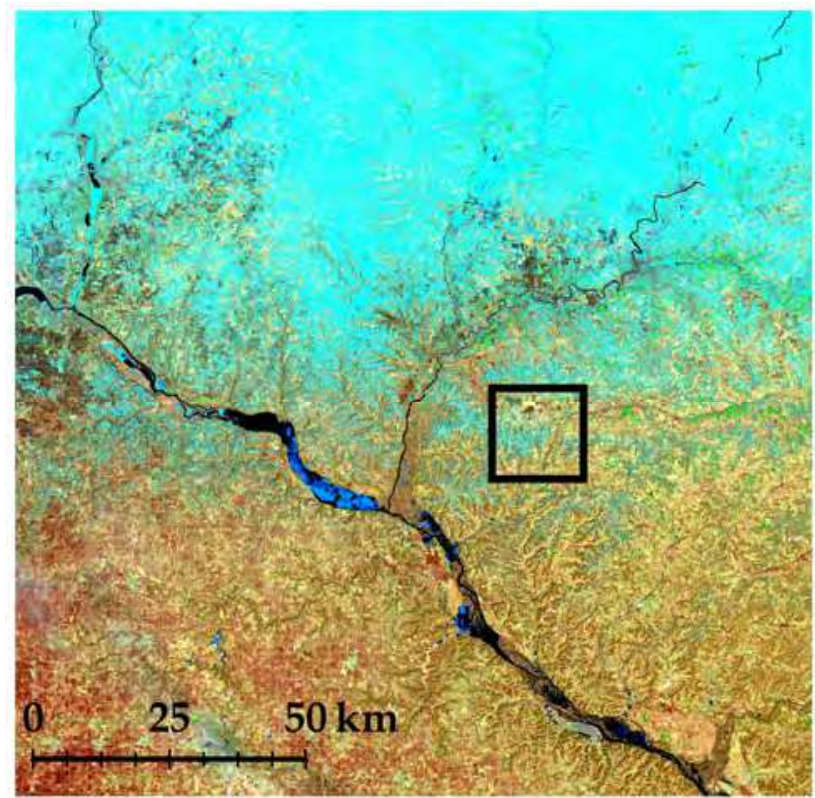

Fig. 2. A false-color composite image comprised of Landsat ETM+ bands 5, 4 and 2 as R,G,B shows snow cover as cyan colors in the northern half of the image. The square box represents the subset in Figure 4. 


\begin{tabular}{|c|c|}
\hline Input Data & $\begin{array}{c}\text { Band pass }(\mu \mathrm{m}) / \\
\text { Equation }\end{array}$ \\
\hline Landsat ETM+ Band 1 & $0.45-0.52$ \\
\hline Landsat ETM+ Band 2 & $0.53-0.61$ \\
\hline Landsat ETM+ Band 3 & $0.63-0.69$ \\
\hline Landsat ETM+ Band 4 & $0.78-0.90$ \\
\hline Landsat ETM+ Band 5 & $1.55-1.75$ \\
\hline Landsat ETM+ Band 7 & $2.09-2.35$ \\
\hline NDSI & $\frac{\text { Band } 4-\text { Band 6 }}{\text { Band } 4+\text { Band 6 }}$ \\
\hline NDVI & $\frac{\text { Band } 4-\text { Band 3 }}{\text { Band } 4+\text { Band 3 }}$ \\
\hline
\end{tabular}

Table 7. Two input-combination permuations to SOM were assessed. The first one included six of the Landsat 7 ETM+ bands (bands 1-5 and band 7), and the second data set included two additional normalized difference index images, which have been demonstrated to be useful in mapping snow in forests (Klein et al., 1998).

\subsection{Methodology}

Image analysis was performed in the IDRISI 16 GIS/remote-sensing software package using the implemented SOM module, which is modeled after the method described in Kohonen (1990). The neural network was run with an initial neighborhood radius of 17.97; a minimum learning rate of 0.5 ; a maximum learning rate of 1 ; and a $12 \times 12$ lattice of output neurons. A k-means clustering was applied to the SOM results, and a maximum of $10 \mathrm{k}-$ means classes/clusters was specified.

Two networks were developed with the same parameters, but with different input combinations. For the first input combination, inputs were the six Landsat ETM+ surface reflectance bands (Table 7). For the SOM with this input combination, the quantization error, which measures the average distance between each input and the neuron to which it is mapped, was 0.0775. For the second input combination, two additional normalized difference index bands were added (Table 7), lowering the quantization error to 0.0169 . Reflectance bands 3 and 4 are used to calculate the Normalized Difference Vegetation Index (NDVI) which captures the inverse relationship between reflectance in the red and nearinfrared portions of the electromagnetic spectrum associated with healthy green vegetation (Jensen, 2005). The index is useful in distinguishing vegetated areas that have higher NDVI values from non-vegetated or sparsely-vegetated areas with lower NVDI values. Normalized Difference Snow Index (NDSI) is calculated using bands 4 and 6, and, similarly to NDVI, it uses the inverse relationship between snow reflectance in the visible and nearinfrared (Hall, 1995). Adding the two index images does not increase the information 
content of the inputs, but it does increase the redundancy in the input data. Redundancy and structure in the input data is one of the principles of self-organization (Haykin, 2009), and therefore, the second input combination would be expected to produce better results.

The performance of SOM in detecting snow-covered pixels using the two input combinations was compared to the MODIS snow-mapping algorithm (SNOMAP) which has a long history of use in mapping snow and is the standard algorithm for producing global daily snow maps from MODIS (Hall, 1995; Hall et al., 2002). SNOMAP maps snow primarily using the NDSI, but a combination of NDSI and NDVI improves snow mapping in forests (Klein et al., 1998). Also, SNOMAP excludes water pixels from analysis (Hall, 1995). To facilitate the comparison of SOM results to SNOMAP, water is masked in the current study.

\subsection{Results and discussion}

The input combination including only reflectance bands returned 10 classes that were subsequently combined into snow-covered and snow-free areas. The resulting snow map has a $92 \%$ overall agreement with SNOMAP (Table 8). Commission errors, where SOM maps snow missed by SNOMAP, were $24.56 \%$, whereas omission errors, pixels mapped as snow by SNOMAP but missed by SOM, is much lower (only 3.71\%).

The second input combination which includes the additional index bands returned only three classes. Two of the classes are easily identified as snow and snow-free. The third class represented a combination of water and snow-covered pixels. Excluding water from the analysis, the remaining third class pixels were considered snow. (Figure 3). The overall agreement between the second SOM result and SNOMAP is 88\% (Table 9). No omission errors occurred, meaning SOM did not miss any of the snow-covered areas mapped by SNOMAP. However, the commission errors were high, e.g., 35.38\% for snow-covered, which is larger than the same error for the reflectance-only input combination.

Both input combinations resulted in a larger area mapped as snow compared to SNOMAP, with the input combination with additional index bands mapping the largest snow-covered area. SNOMAP mapped $4,499 \mathrm{~km}^{2}$ as snow; SOM with the first input data combination mapped 5,703 $\mathrm{km}^{2}$; and SOM with the second input combination mapped $6,915 \mathrm{~km}^{2}$ as snow.

The errors of commission between the input combination with additional index bands and SNOMAP were examined visually (Figure 4). The area mapped as snow by SOM appears to be snow-covered in the false color-composite of Landsat bands 5, 4 and 2, but failed to be mapped as snow by SNOMAP. So even though the second input combination has lower

\begin{tabular}{|c|c|c|}
\hline \multirow{2}{*}{$\begin{array}{l}\text { Reflectance Bands } \\
\text { Only }\end{array}$} & Snow & Snow-Free \\
\cline { 2 - 3 } & $4,779,553(21.075 \%)$ & $1,556,011(6.86 \%)$ \\
\hline Snow & $184,057(0.81 \%)$ & $16,167,435(71.26 \%)$ \\
\hline \multicolumn{2}{|c|}{ Snow-Free } & \\
\hline Overall agreement: 92\%
\end{tabular}

Table 8. Confusion matrix between SNOMAP and SOM with reflectance bands only as input shows number of pixels that are in agreement or disagreement. Numbers in parenthesis indicate percentage of total count. 


\begin{tabular}{|c|c|c|}
\hline \multirow{2}{*}{$\begin{array}{l}\text { Reflectance and Index } \\
\text { Bands }\end{array}$} & \multicolumn{2}{|c|}{ SNOMAP } \\
\cline { 2 - 3 } & Snow & Snow-Free \\
\hline Snow & $4,963,610(21.88 \%)$ & $2,718,029(11.98 \%)$ \\
\hline Snow-Free & $0(0 \%)$ & $15,005,417(66.14 \%)$ \\
\hline Overall agreement: $88 \%$ & \\
\hline
\end{tabular}

Table 9. Confusion matrix between SNOMAP and SOM with both reflectance bands and index bands as input, indicating number of pixels and percent agreement and disagreement.

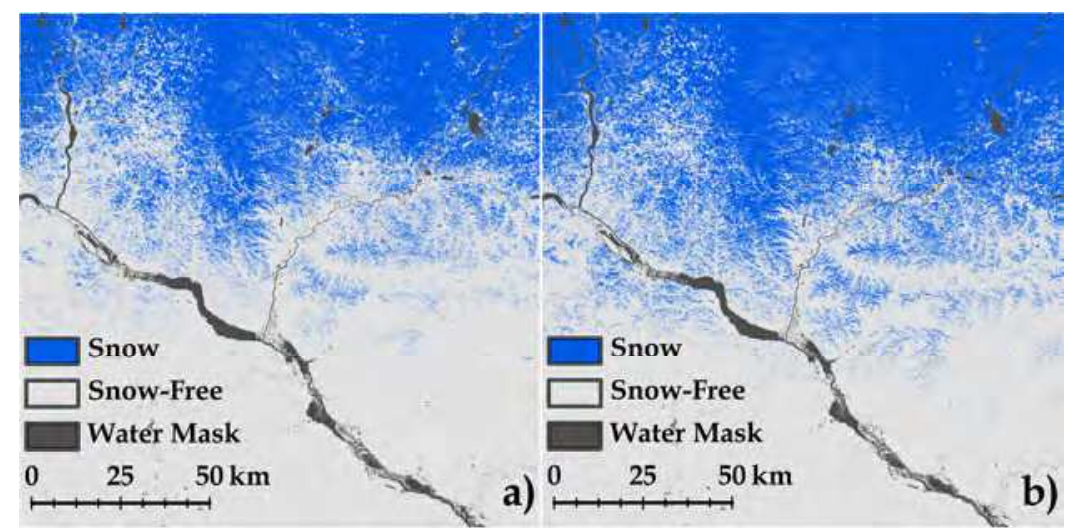

Fig. 3. Snow maps produced by SNOMAP (a) map lesser snow-cover extent compared to the snow maps produced by SOM with both reflectance bands (not illustrated) and index bands (b) as input.
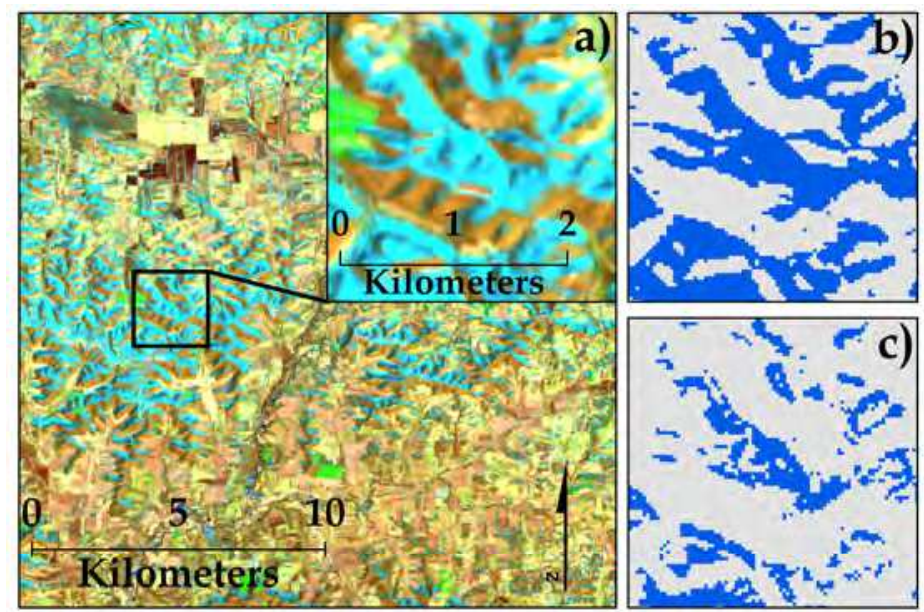

Fig. 4. Portion of false-color image composite examined (a). Comparing the results of SOM with both reflectance bands and index bands as input (b) and SNOMAP (c) shows that the larger snow-cover extent derived by SOM appears more correct. 
overall accuracy as compared to SNOMAP than the first input combination, it appears to provide more accurate snow mapping. However, further validation of the SOM results requires the use of field observations or higher-resolution images. Note that the "errors" stated in study may not technically be considered as errors per se, as we treated the SNOMAP result as reference data, rather than obtaining ground reference data.

\section{Conclusion}

SOM-based and SOM-related techniques have been applied in remote sensing. Imageanalysis tasks range from identifying synoptic-scale ocean or atmospheric characteristics to land-cover classification. The utility of the Kohonen SOM as an unsupervised classification technique was demonstrated here by generating a snow map based upon a Landsat 7 ETM+ image. SOM-mapping of snow compares favorably to the widely-used SNOMAP algorithm, which has a considerable heritage in mapping snow from satellite images. In the single test image, the SOM mapped snow that SNOMAP missed. Better results were achieved when the input bands were complimented by index bands, which increased the redundancy in the input.

\section{References}

Bagan, H.; Wang, Q.; Watanabe, M.; Karneyarna, S. \& Bao, Y. (2008). Land-cover classification using ASTER multi-band combinations based on wavelet fusion and SOM neural network. Photogrammetric Engineering and Remote Sensing, Vol. 74, No. 3, 333-342, ISSN 0099-1112

Baraldi, A.; Blonda, P.; Parmiggiani, F.; Pasquariello, G. \& Satalino, G. (1998). Model transitions in descending FLVQ. IEEE Transactions on Neural Networks, Vol. 9, No. 5, 724- 738, ISSN 1045-9227

Benz, U. C. (1999). Supervised fuzzy analysis of single- and multichannel SAR data. IEEE Transactions on Geoscience and Remote Sensing, Vol. 37, No. 2, 1023-1037, ISSN 0196-2892

Bezdek, J. C. \& Pal, N. R. (1995). Two soft relatives of learning vector quantization. Neural Networks, Vol. 8, No. 5, 729-743, ISSN 0893-6080

Blonda, P.; Bennardo, A.; Satalino, G. \& Forgia, V. (1995). Application of the unsupervised fuzzy Kohonen clustering network for remote sensed data segmentation. In A. Bonarini; D. Mancini; F. Masulli \& A. Petrosino (Eds.), Proceedings of WILF '95, Italian workshop on fuzzy logic: New trends in fuzzy logic, pp. 143- 150, Naples, Italy, September 1995, World Scientific, River Edge, NJ

Blonda, P.; la Forgia, V.; Pasquariello, G. \& Satalino, G. (1996). Feature extraction and pattern classification of remote sensing data by a modular neural system. Optical Engineering, Vol. 35, No. 2, 536-542, ISSN 0091-3286

Boekaerts, P.; Nyssen, E. \& Cornelis, J. (1995). Autoadaptive mono-spectral cloud identification in Meteosat satelliete images, In Image and Signal Processing for Remote Sensing II, J. Desachy, Ed., Proceedings of SPIE, pp. 259-271, Vol. 2579, Paris, France, September 1995 
Ceccarelli, M.; Farina, A. \& Petrosino, A. (1995). Fuzzy unsupervised terrain classification based on a multiresolution approach. In A. Bonarini, D. Mancini, F. Masulli \& A. Petrosino (Eds.), Proceedings of WILF'95, Italian workshop on fuzzy logic: New trends in fuzzy logic, pp. 151- 159, Naples, Italy, September 1995, World Scientific, River Edge, NJ

Congalton, R.G. \& Green, K. (1999). Assessing the Accuracy of Remotely Sensed Data: Principles and Practices, Lewis, Boca Raton, FL, ISBN 0-873-71986-7

Doucette, P.; Agouris, P. \& Stefanidis, A. (2008). Self-Organising Map Principles Applied Towards Automatic Road Extraction from Remotely Sensed Imagery, InSelfOrganising Maps. Applications in Geographic Information Science, Skupin, A., (Ed.), 177-194, Wiley, ISBN 978-0-470-02167-5, West Sussex

Ehsani, A. H. \& Quiel, F. (2008). Application of self organizing map and SRTM data to characterize yardangs in the Lut desert, Iran. Remote Sensing of Environment, Vol. 112, No. 7, 3284-3294, ISSN 0034-4257

Filippi, A. M.; Brannstrom, C.; Dobreva, I.; Cairns, D. M. \& Kim, D. (2009). Unsupervised fuzzy ARTMAP classification of hyperspectral Hyperion data for savanna and agriculture discrimination in the Brazilian Cerrado. GIScience E Remote Sensing, Vol. 46, No. 1, 1-23, ISBN 1548-1603

Filippi, A. M. \& Jensen, J. R. (2006). Fuzzy learning vector quantization for hyperspectral coastal vegetation classification. Remote Sensing of Environment, Vol. 100, No. 4, 512530, ISSN 0034-4257

Filippi, A. M. \& Jensen, J. R. (2007). Effect of continuum removal on hyperspectral coastal vegetation classification using a fuzzy learning vector quantizer. IEEE Transactions on Geoscience and Remote Sensing, Vol. 45, No. 6, 1857-1869, ISSN 0196-2892

Furrer, R.; Barsch, A.; Olbert, C. \& Schaale, M. (1994). Multispectral imaging of land surface. GeoJournal, Vol. 32, No. 1, 7-16, ISSN 0343-2521

Gonçalves, M. L.; Netto, M. L. A.; Costa, J. A. F. \& Zullo Júnior, J. (2008). An unsupervised method of classifying remotely sensed images using Kohonen self-organizing maps and agglomerative hierarchical clustering methods. International Journal of Remote Sensing, Vol. 29, No. 11, 3171-3207, ISSN 0143-1161

Guijarro, M. \& Pajares, G. (2009). On combining classifiers through a fuzzy multicriteria decision making approach: Applied to natural textured images. Expert Systems with Applications, Vol. 36, No. 3, 7262-7269, ISSN 0957-4174

Hall, D. K.; Riggs, G. A. \& Salomonson, V. V. (1995). Development of methods for mapping global snow cover using moderate resolution imaging spectroradiometer data. Remote Sensing of Environment, Vol. 54, No. 2 , 127-140, ISSN 0034-4257

Hall, D. K.; Riggs, G. A.; Salomonson, V. V.; DiGirolamo, N. E. \& Bayr, K. J. (2002). MODIS snow-cover products. Remote Sensing of Environment, Vol. 83, No. 1-2, 181-194, ISSN 0034-4257

Hassoun, M. H. (1995). Fundamentals of Artificial Neural Networks. MIT Press, Cambridge, MA, ISBN 0-262-08239-X

Haykin, S. (2009). Neural Networks and Learning Machines, Pearson Education, ISBN 013147139-2, Upper Saddle River

Hewitson, B. C. \& Crane, R. G. (2002). Self-organizing maps: applications to synoptic climatology. Climate Research, Vol. 22, No. 1, 13-26, ISSN 0936-577X 
Hillermeier, C.; Kunstmann, N.; Rabus, B. \& Tavan, P. (1994). Topological feature maps with self-organized lateral connections: a population-coded one-layer model of associative memory. Biological Cybernetics, Vol. 72, 103-117, No. 2, 103-117, ISSN 0340-1200

Hong, Y.; Chiang, Y. M.; Liu, Y.; Hsu, K. L. \& Sorooshian, S. (2006). Satellite-based precipitation estimation using watershed segmentation and growing hierarchical self-organizing map. International Journal of Remote Sensing, Vol. 27, No. 23-24, 51655184, ISSN 0143-1161

Huntsberger, T. L. \& Ajjimarangsee, P. (1990). Parallel self-organizing feature maps for unsupervised pattern recognition. International Journal of General Systems, Vol. 16, No. 4, 357-372, ISSN 0308-1079

Ito, Y. \& Omatu, S. (1997). Category classification method using a self-organizing neural network. International Journal of Remote Sensing, Vol. 18, No. 4, 829-845, ISSN 01431161

Jensen, J. R. (2005). Introductory Digital Image Processing: A Remote Sensing Perspective, 3rd Ed., Pearson Education, ISBN 0-13-145361-0, Upper Saddle River

Ji, C. Y. (2000). Land-use classification of remotely sensed data using Kohonen SelfOrganizing Feature Map neural networks. Photogrammetric Engineering and Remote Sensing, Vol. 66, No. 12, 1451-1460, ISSN 0099-1112

Klein, A. G.; Hall, D. K. \& Riggs, G. A. (1998). Improving snow cover mapping in forests through the use of a canopy reflectance model. Hydrological Processes, Vol. 12, No. 10-11, 1723-1744, ISSN 0885-6087

Kohonen, T. (1988). Self-Organization and Associative Memory, Springer-Verlag, ISBN 0-38718314-0, New York, Berlin, Heidelberg

Kohonen, T. (1990). The Self-Organizing Map. Proceedings of the IEEE, Vol. 78, pp. 1464-1480, ISSN 0018-9219, September 1990

Kohonen, T. (2001). Self-Organizing Maps. Springer-Verlag, ISBN 3-540-67921-9, New York, Berlin, Heidelberg

Latif, B. A.; Lecerf, R.; Mercier, G. \& Hubert-Moy, L. (2008). Preprocessing of low-resolution time series contaminated by clouds and shadows. IEEE Transactions on Geoscience and Remote Sensing, Vol. 46, No. 7, 2083-2096, ISSN 0196-2892

Lee, S. \& Lathrop, R. G. (2006). Subpixel analysis of Landsat ETM+ using Self-Organizing Map (SOM) neural networks for urban land cover characterization. IEEE Transactions on Geoscience and Remote Sensing, Vol. 44, No. 6, 1642-1654, ISSN 01962892

Li, R. \& Si, H. (1992). Multi-spectral image classification using improved backpropagation neural networks, In Proceedings of the IEEE International Geosciences and Remote Sensing Symposium, (IGARSS ‘92), Vol. 2, pp. 1078-1080, Houston, TX, May 1992

Lin, C. T. \& Lee, C. S. G. (1996). Neural fuzzy systems: A neuro-fuzzy synergism to intelligent systems. Prentice Hall P T R, Upper Saddle River, NJ, ISBN 0-132-35169-2

Lin, C. T.; Lee, Y. C. \& Pu, H. C. (2000). Satellite sensor image classification using cascaded architecture of neural fuzzy network. IEEE Transactions on Geoscience and Remote Sensing, Vol. 38, No. 2, 1033-1043, ISSN 0196-2892

Liu, Y., Weisberg, R. H. \& He, R. (2006). Sea surface temperature patterns on the West Florida Shelf using the growing hierarchical self-organizing maps. Journal of Atmospheric and Oceanic Technology, Vol. No. 2, 23, 325-328, ISSN 0739-0572 
Liu, Y. G., Weisberg, R. H. \& Shay, L. K. (2007). Current patterns on the West Florida Shelf from joint self-organizing map analyses of HF radar and ADCP data. Journal of Atmospheric and Oceanic Technology, Vol. 24, No. 4, 702-712, ISSN 0739-0572

Marques, N. C. \& Chen, N. (2003) Border detection on remote sensing satellite data using self-organizing maps, Proceedings of EPIA 2003 - 11th Portuguese conference on Artificial Intelligence, pp. 294-307, ISBN 3-540-20589-6, Beja, Portugal, December 2003, Springer-Verlag, Berlin

Mendenhall, M. J. \& Merényi, E. (2008). Relevance-based feature extraction for hyperspectral images. IEEE Transactions on Neural Networks, Vol. 19, No. 4, 658-672, ISSN 10459227

Molinier, M.; Laaksonen, J. \& Hame, T. (2007). Detecting man-made structures and changes in satellite imagery with a content-based information retrieval system built on selforganizing maps. IEEE Transactions on Geoscience and Remote Sensing, Vol. 45, No. 4, 861-874, ISSN 0196-2892

MRLC, (2009). National Land Cover Database, http://www.mrlc.gov/index.php

NASA, (2009). Landsat 7: Science Data Users Handbook, http://landsathandbook.gsfc.nasa.gov/handbook/handbook_toc.html

Olbert, C.; Schaale, M. \& Furrer, R. (1995). Mapping of forest fire damages using imaging spectroscopy. Advances in Space Research, Vol. 15, No. 11, (11)115-(11)122, ISSN 0273-1177

Qiu, F. (2008). Neuro-fuzzy based analysis of hyperspectral imagery. Photogrammetric Engineering and Remote Sensing, Vol. 74, No. 10, 1235-1247, ISSN 0099-1112

Qiu, F. \& Jensen, J. R. (2004). Opening the black box of neural networks for remote sensing image classification. International Journal of Remote Sensing, Vol. 25, No. 9, 1749-1768, ISSN 0143-1161

Ramsey, M. C.; Chen, H.; Zhu, B. \& Schatz, B. R. (1999). A collection of visual thesauri for browsing large collections of geographic images. Journal of the American Society for Information Science, Vol. 50, No. 9, 826-834, ISSN 1097-4571

Richardson, A. J.; Risien, C. \& Shillington, F. A. (2003). Using self-organizing maps to identify patterns in satellite imagery. Progress in Oceanography, Vol. 59, No. 2-3, 223239, ISSN 0079-6611

Schaale, M., \& Furrer, R. (1995). Land surface classification by neural networks. International Journal of Remote Sensing, Vol. 16, No. 16, 3003-3031, ISSN 0143-1161.

Solaiman, B. \& Mouchot, M. C. (1994). A comparative study of conventional and neural network classification of multispectral data, In Proceedings of the International Geoscience and Remote Sensing Symposium (IGARSS '94), Surface and Atmospheric Remote Sensing: Technologies, Data Analysis and Interpretation, pp. 1413-1415, ISBN 0-7803-1497-2, Pasadena, CA, August 1994

Tsao, E. C. -K.; Bezdek, J. C. \& Pal, N. R. (1994). Fuzzy Kohonen clustering networks. Pattern Recognition, Vol. 27, No. 5, 757- 764, ISSN 0031-3203

Villmann, T.; Merenyi, E. \& Hammer, B. (2003). Neural maps in remote sensing image analysis. Neural Networks, Vol. 16, No. 3-4, 389-403, ISSN 0893-6080

Wan, W. \& Fraser, D. (1999). Multisource data fusion with Multiple Self-Organizing Maps. IEEE Transactions on Geoscience and Remote Sensing, Vol. 37, No. 3, 1344-1349, ISSN 0196-2892 
Wan, W. J. \& Fraser, D. (2000). A Multiple Self-Organizing Map scheme for remote sensing classification, Proceedings of Multiple Classifier Systems, First International Workshop, MCS 2000, pp. 300-309, ISBN 3-540-67704-6, Cagliari, Italy, June, 2000, Springer-Verlag, Berlin

Yoshida, T. \& Omatu, S. (1994). Neural network approach to land cover mapping. IEEE Transactions on Geoscience and Remote Sensing, Vol. 32, No. 5, 1103-1109, ISSN 01962892 


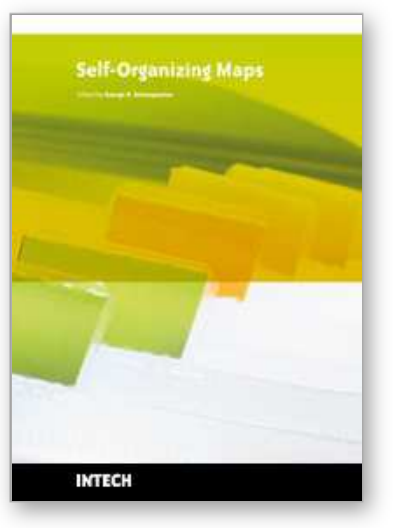

\author{
Self-Organizing Maps \\ Edited by George K Matsopoulos
}

ISBN 978-953-307-074-2

Hard cover, 430 pages

Publisher InTech

Published online 01, April, 2010

Published in print edition April, 2010

The Self-Organizing Map (SOM) is a neural network algorithm, which uses a competitive learning technique to train itself in an unsupervised manner. SOMs are different from other artificial neural networks in the sense that they use a neighborhood function to preserve the topological properties of the input space and they have been used to create an ordered representation of multi-dimensional data which simplifies complexity and reveals meaningful relationships. Prof. T. Kohonen in the early 1980s first established the relevant theory and explored possible applications of SOMs. Since then, a number of theoretical and practical applications of SOMs have been reported including clustering, prediction, data representation, classification, visualization, etc. This book was prompted by the desire to bring together some of the more recent theoretical and practical developments on SOMs and to provide the background for future developments in promising directions. The book comprises of 25 Chapters which can be categorized into three broad areas: methodology, visualization and practical applications.

\title{
How to reference
}

In order to correctly reference this scholarly work, feel free to copy and paste the following:

Anthony Filippi, Iliyana Dobreva, Andrew G. Klein and John R. Jensen (2010). Self-Organizing Map-based Applications in Remote Sensing, Self-Organizing Maps, George K Matsopoulos (Ed.), ISBN: 978-953-307-0742, InTech, Available from: http://www.intechopen.com/books/self-organizing-maps/self-organizing-map-basedapplications-in-remote-sensing

\section{INTECH}

open science | open minds

\section{InTech Europe}

University Campus STeP Ri

Slavka Krautzeka 83/A

51000 Rijeka, Croatia

Phone: +385 (51) 770447

Fax: +385 (51) 686166

www.intechopen.com

\section{InTech China}

Unit 405, Office Block, Hotel Equatorial Shanghai

No.65, Yan An Road (West), Shanghai, 200040, China

中国上海市延安西路65号上海国际贵都大饭店办公楼405单元

Phone: +86-21-62489820

Fax: +86-21-62489821 
(C) 2010 The Author(s). Licensee IntechOpen. This chapter is distributed under the terms of the Creative Commons Attribution-NonCommercialShareAlike-3.0 License, which permits use, distribution and reproduction for non-commercial purposes, provided the original is properly cited and derivative works building on this content are distributed under the same license. 